\title{
KONTRIBUSI KECEPATAN BERGERAK, REAKSI KAKI, DAN DAYA LEDAK TUNGKAI TERHADAP KEMAMPUAN LARI 100 METER PADA SISWA SMK NEGERI 2 MAKASSAR
}

\author{
Muhammad Harliawan1, Andi Ogo Darminto \\ Prodi Pendidikan Kepelatihan Olahraga ${ }^{1,2}$ \\ STKIP Muhammadiyah Bone ${ }^{1,2}$ \\ harliawanwawan@gmail.com ${ }^{1}$
}

\begin{abstract}
Abstrak
Penelitian dilakukan yang bertujuan untuk mengetahui kontribusi kecepatan bergerak, reaksi kaki, dan daya ledak tungkai terhadap kemampuan lari 100 meter pada siswa SMK Negeri 2 Makassar. Penelitian ini merupakan penelitian deskriptif dengan teknik kontribusi, yaitu mencari kontribusi antara variabel-variabel yang satu dengan variabel yang lainnya. Adapun sampel yang diambil dan digunakan dalam penelitian ini adalah 40 orang siswa putra SMK Negeri 2 Makassar. Data yang dikumpulkan meliputi: kecepatan bergerak, daya ledak tungkai, dan kemampuan lari 100 meter dan kontribusinya terhadap kemampuan lari 100 meter. Penyajian hasil analisis data meliputi analisis statistik deskriptif dan inferensial. Analisis data yang digunakan dalam penelitian ini adalah analisis dengan teknik statistik inferensial. Berdasarkan hasil analisis data yang didapatkan, berikut ini adalah kesimpulan yang didapatkan, antara lain adalah bahwa kecepatan bergerak, reaksi kaki, dan daya ledak tungkai memberikan kontribusi yang signifikan terhadap kecepatan lari 100 meter. Hasil penelitian ini bisa dijadikan acuan kepada para pelatih dan guru olahraga dalam mengajar atau melatih cabang olahraga lari 100 meter.
\end{abstract}

Kata Kunci: kecepatan bergerak, reaksi kaki, daya ledak tungkai, lari

\section{THE CONTRIBUTION OF MOVING SPEED, LEG REACTION, AND DAYA LEDAK TUNGKAI TOWARDS 100 METERS RUNNING ABILITY IN STUDENTS OF SMK NEGERI 2 MAKASSAR}

\begin{abstract}
The research has been conducted with aims to determine the contribution of moving speed, leg-reaction and leg explosive power towards 100 meters running ability in students of SMK Negeri 2 Makassar. This research was descriptive study with using distribution technique which looking for the corelation and contribution of each variable. Then research samples taken and used in this study were 40 students of SMK Negeri 2 Makassar. Data was collected including: moving speed, leg reaction, and leg explosive power and their contribution to the ability of 100 meters running. The research results were analyzed by using descriprive and inferential technique, Based on the results of the analysis of the data obtained, the following conclusions are obtained, among others, that the speed of movement, leg reaction, and leg explosive power contribute significantly to the running speed of 100 meters. The results of this study can be used as a reference to the trainers and sports teachers in teaching or training the 100 meter sprint.
\end{abstract}

Keywords: moving speed, leg reaction, explosive power, running

Correspondence author: Muhammad Harliawan, Andi Ogo Darminto STKIP Muhammadiyah Bone, Indonesia. E-Mail: harliawanwawan@gmail.com 
Kontribusi Kecepatan Bergerak, Reaksi Kaki, dan Daya Ledak Tungkai terhadap Kemampuan Lari

Jurnal HalamanOlahraga Nusantara licensed under a Creative Commons Attribution-ShareAlike 4.0 International License.

\section{PENDAHULUAN}

Cabang olahraga atletik merupakan induk dari semua cabang olahraga, dimana gerakan-gerakan yang ditampilkan merupakan gerakan dasar (Muhtar \& Irawati, 2009). Jarver (2005) mengemukakan bahwa gerakan dasar tersebut terdiri dari; lari, jalan, lempar (tolak), dan lompat (loncat). Sehubungan dengan banyaknya nomor-nomor dalam cabang olahraga atletik (Bahagia, 2012), maka yang menjadi obyek dalam penelitian ini dan penulisan ilmiah ini hanya terfokus pada gerakan lari. Namun demikian, nomor lari juga terdiri dari jarak pendek, menengah dan jauh. Ketiga jarak lari tersebut yeng menjadi perhatian hanya jarak pendek yang masih perlu dibenahi. Jelas bahwa pada gerakan tersebut sangat dibutuhkan semua cabang olahraga lainnya termasuk salah satunya pada lompat jangkit (Sugarwanto and Okilanda., 2020) juga membutuhkan kecepatan lari sebelumnya.

Peranan kemampuan fisik dalam menunjang prestasi lari 100 meter sangat penting, sehingga atlet yang mempunyai kemampuan fisik yang baik tentu akan lebih berpeluang untuk berprestasi. Kadar asam laktat juga memiliki peran besar mempengaruhi (Aswan and Harliawan., 2019) maksimalnya lari 100 meter. Sebaliknya juga apabila atlet memiliki kemampuan fisik yang baik tentunya sulit dicegah dari maksimalnya asam laktat untuk mencapai finish. Pentingnya fisik bagi seorang atlet lari 100 meter berpengaruh juga dengan hasil kecepatan yang tidak terpengaruh dengan asam laktat, sehingga sebelum terjun ke arena perlombaan atlet harus sudah memiliki kondisi fisik yang baik hasil latihan. Keberadaan kondisi fisik yang siap bertujuan agar dalam suatu perlombaan dapat menghadapi intensitas kerja dan gejala stress yang bakal dihadapinya dalam suatu perlombaan (Mureika, 2005).

Berdasarkan pengamatan selama ini dapat dikemukakan bahwa atlet lari 100 meter selain mengenai fisik yang kurang memadai, juga sebagian besar masih kurang dalam hal penguasaan kemampuan teknik dasar lari yang benar. Untuk meningkatkan kemampuan lari 100 meter, maka kebiasaan-kebiasaan yang 
salah perlu diperbaiki. Salah satu yang harus diperhatikan adalah dengan memperbanyak bentuk latihan fisik untuk meningkatkan performas yang dilihat dari kecepatan gerak kaki, reaksi kaki, dan daya ledak tungkai, serta untuk mendukung keberhasilan dalam melakukan gerakan lari 100 meter.

Kecepatan adalah komponen kondisi fisik yang esensial dalam cabang olahraga. Bafirman \& Wahyuri (2019), mengemukakan bahwa : Kecepatan adalah kemampuan badan mengarahkan strukturnya dengan sebuah sistem untuk mengalahkan beban, jarak dan waktu menghasilkan kerja mekanik berpindah dari satu tempat ke tempat lain dengan singkat. Kecepatan dalam hal ini merupakan kecepatan bergerak untuk dapat melakukan pergerakan kaki yang cepat untuk mampu mengayunkan kaki bergerak ke depan dengan cepat. Oleh karena, untuk menghasilkan kecepatan bergerak yang cepat diperlukan kecepatan gerak kaki sebagai daya dorong untuk membantu gerakan tungkai pada saat melakukan ayunan.

Kecepatan reaksi merupakan salah satu bagian dari komponen kecepatan. Bafirman and Wahyuri (2019) menyampaikan bahwa kecepatan rekasi merupakan tanggapan dari respon tubuh menerima stimulus dengan cepat sehingga melakukan perpindahan. Kecepatan reaksi kaki sangat penting guna memberikan akselerasi (Tangkudung \& Puspitorini, 2006) pada lari 100 meter utama sekali pada saat start dilakukan. Kecepatan reaksi merupakan kecepatan yang menjawab suatu rangsangan atau stimulus dengan cepat yang dapat berupa penglihatan, suara melalui pendengaran, dan juga berarti kemampuan suatu otot atau sekelompok otot untuk bereaksi secepat mungkin setelah mendapat stimulus.

Daya ledak tungkai merupakan perpaduan antara kecepatan dan kekuatan pada tungkai (Lumintuarso, 2013). Daya ledak tungkai sangat penting di setiap aktifitas pada cabang olahraga terutama yang mengharuskan menggunakan tungkai dalam aktivitas berolahraga. Daya ledak merupakan kemampuan otot untuk melepaskan dari tahanan dengan kontraksi yang sangat cepat dalam waktu yang tepat sesuai dengan yang dikehendaki (Bafirman \&Wahyuri, 2019). Sehingga untuk memberikan tenaga pada tungkai dengan cepat dan kuat dalam waktu yang sangat singkat serta memberikan momentum sebaik mungkin pada 
tubuh untuk dapat menghasilkan kecepatan lari 100 meter yang cepat memerlukan daya ledak tungkai.

Inilah yang mendorong peneliti untuk membuktikan apakah kecepatan bergerak, reaksi kaki dan daya ledak tungkai mempunyai kontribusi. Sehingga peneliti mengangkat judul sebagai berikut : "Kontribusi Kecepatan Bergerak, Reaksi Kaki, Dan Daya Ledak Tungkai Terhadap Kemampuan Lari 100 Meter Pada Siswa SMK Negeri 2 Makassar".

\section{METODE}

Penelitian ini merupakan penelitian deskriptif dengan teknik kontribusi, yaitu mencari kontribusi antara variabel-variabel yang satu dengan variabel yang lainnya (Sugiyono, 2016). Adapun sampel yang diambil dan digunakan dalam penelitian ini adalah 40 orang siswa putra SMK Negeri 2 Makassar. Data yang dikumpulkan meliputi: kecepatan bergerak, daya ledak tungkai, dan kemampuan lari 100 meter (Widiastuti, 2011) dan kontribusinya terhadap kem ampuan lari 100 meter. Penelitian dilaksanakan pada bulan februari 2020. Adapun teknik analisis data tersebut, digunakan uji statistik korelasional dengan bantuan paket SPSS. Analisis yang dimaksud dalam penelitian ini adalah analisis deskriptif, dan infrensial. Analisis deskriptif untuk menggambarkan data apa adanya. Sedangkan analisis infrensial untuk menguji hipotesis dengan menggunakan analisis regresi sederhana dan analisis regresi ganda.

\section{HASIL DAN PEMBAHASAN}

Penyajian hasil analisis data meliputi analisis statistik deskriptif dan inferensial. Analisis data yang digunakan dalam penelitian ini adalah analisis dengan teknik statistik inferensial. Analisis data secara deskriptif dimaksudkan untuk mendapatkan gambaran umum data meliputi rata-rata, standar deviasi, varians, data maximum, data minimum, range, tabel frekuensi dan grafik. Tabel 1 di bawah ini menunjukkan rangkuman hasil analisis deskriptif tiap variabel. 
Kontribusi Kecepatan Bergerak, Reaksi Kaki, dan Daya Ledak Tungkai terhadap Kemampuan Lari 100 Meter pada Siswa SMK Negeri 2 Makassar

Tabel 1. Rangkuman Hasil Analisis Deskriptif tiap Variabel

\begin{tabular}{ccccccc}
\hline Nilai Statistik & N & Rata-rata & Std. Deviasi & Min & Max & Range \\
\hline KBG & 40 & 35.35 & 3.40 & 30.00 & 43.00 & 13.00 \\
RG & 40 & 0.2 & 0.02 & 0.20 & 0.36 & 0.16 \\
DLT & 40 & 2.01 & 0.07 & 1.90 & 2.15 & 0.25 \\
L100M & 40 & 18.77 & 1.04 & 16.77 & 20.95 & 4.18 \\
\hline
\end{tabular}

Keterangan:

KBG : Kecepatan bergerak

RK : Reaksi kaki

DLT : Daya ledak tungkai

L100M: Kecepatan lari 100 meter

Dari tabel 1 di atas sudah dapat diperoleh gambaran tentang data kecepatan bergerak, reaksi kaki, daya ledak tungkai dan kecepatan lari 100 meter siswa SMK Negeri 2 Makassar sebagai berikut:

- Kecepatan bergerak siswa SMK Negeri 2 Makassar, diperoleh nilai rata-rata 35.35 standar deviasi 3.40, nilai minimum 30.00 nilai maksimum 43.00, rentang 13.00 .

- Reaksi kaki siswa SMK Negeri 2 Makassar, diperoleh nilai rata-rata 0.25 dtk, standar deviasi 0.02 dtk, nilai minimum 0.36 dtk, nilai maksimum 0.20 dtk, rentang $0.16 \mathrm{dtk}$.

- Daya ledak tungkai siswa SMK Negeri 2 Makassar, diperoleh nilai rata-rata 2.01, standar deviasi 0.07 , nilai minimum 1.90, nilai maksimum 2.15, rentang 0.25

- Kecepatan lari 100 meter siswa SMK Negeri 2 Makassar, diperoleh nilai ratarata 18.77 , standar deviasi 1.04 , nilai minimum 16.77, nilai maksimum 20.95 , rentang 4.18

Untuk mengetahui apakah data kecepatan bergerak, reaksi kaki, daya ledak tungkai dan kecepatan lari 100 meter pada siswa SMK Negeri 2 Makassar berdistribusi normal, maka dilakukan pengujian dengan menggunakan uji Kolmogorov Smirnov. Hasil uji normalitas data dapat dilihat pada Tabel 2. 
Kontribusi Kecepatan Bergerak, Reaksi Kaki, dan Daya Ledak Tungkai terhadap Kemampuan Lari 100 Meter pada Siswa SMK Negeri 2 Makassar

Tabel 2. Rangkuman Hasil Uji Normalitas Data Tiap Variabel

\begin{tabular}{ccccccc}
\hline Variabel & Absolut & Positif & Negatif & S-Z & Prob. & Ket. \\
\hline KBG & 0.124 & 0.124 & -0.064 & 0.787 & 0.566 & Normal \\
RG & 0.159 & 0.159 & -0.155 & 1.005 & 0.265 & Normal \\
DLT & 0.151 & 0.130 & -0.151 & 0.953 & 0.324 & Normal \\
L100M & 0.105 & 0.105 & -0.079 & 0.664 & 0.769 & Normal \\
\hline
\end{tabular}

Oleh karena data penelitian untuk kecepatan bergerak, reaksi kaki, daya ledak tungkai dan kecepatan lari 100 meter berdistribusi normal $(\mathrm{P}>0.05)$, maka digunakan uji statistik parametrik yaitu analisa regresi.

Analisa regresi dilakukan untuk menguji hipotesis yang diajukan melalui data empiris yang diperoleh di lapangan melalui hasil tes dan pengukuran terhadap variabel yang diteliti meliputi kecepatan bergerak, reaksi kaki, dan daya ledak tungkai. Hasil uji regresi dijabarkan sebagai berikut:

a. Regresi sederhana kecepatan bergerak terhadap kecepatan lari 100 meter pada siswa SMK Negeri 2 Makassar

Data kecepatan bergerak diperoleh melalui tes side step. Rangkuman hasil analisis data untuk mengetahui kontribusi kecepatan gerak terhadap kecepatan lari 100 meter dapat dilihat pada tabel 3.

Tabel 3. Regresi kecepatan bergerak terhadap kecepatan lari 100 meter

\begin{tabular}{cccc}
\hline Variabel & $\mathrm{R}_{0}$ & $\mathrm{P}$ & Keterangan \\
\hline KBG (X1) & 0.722 & 0.000 & Signifikan \\
L100M (Y) & & & \\
\hline
\end{tabular}

Berdasarkan tabel 3 di atas terlihat bahwa hasil perhitungan regresi, diperoleh dengan nilai regresi $\mathrm{R}$ hitung $(\mathrm{Ro})=0.722(\mathrm{P}<0,05)$, berarti ada kontribusi yang signifikan kecepatan bergerak terhadap kecepatan lari 100 meter pada siswa SMK Negeri 2 Makassar. Dengan demikian jika siswa memiliki kecepatan bergerak yang cepat akan diikuti dengan hasil kecepatan lari 100 meter yang cepat pula. 
Kontribusi Kecepatan Bergerak, Reaksi Kaki, dan Daya Ledak Tungkai terhadap Kemampuan Lari 100 Meter pada Siswa SMK Negeri 2 Makassar

b. Regresi sederhana reaksi kaki terhadap kecepatan lari 100 meter pada siswa SMK Negeri 2 Makassar.

Data reaksi kaki diperoleh melalui tes whole body reaction. Untuk mengetahui keeratan kontribusi reaksi kaki terhadap kecepatan lari 100 meter dilakukan analisis regresi. Rangkuman hasil analisis data dapat dilihat pada tabel 4.

Tabel 4. Regresi reaksi kaki terhadap kecepatan lari 100 meter

\begin{tabular}{cccc}
\hline Variabel & $\mathrm{R}_{0}$ & $\mathrm{P}$ & Keterangan \\
\hline RK $(\mathrm{X} 2)$ & 0.747 & 0.000 & Signifikan \\
L100M (Y) & & & \\
\hline
\end{tabular}

Berdasarkan tabel 4 di atas terlihat bahwa hasil perhitungan regresi, diperoleh dengan nilai regresi $\mathrm{R}$ hitung $(\mathrm{Ro})=0.747(\mathrm{P}<0,05)$, berarti ada kontribusi yang signifikan reaksi kaki terhadap kecepatan lari 100 meter pada siswa SMK Negeri 2 Makassar. Dengan demikian jika siswa memiliki reaksi kaki yang cepat akan diikuti dengan hasil kecepatan lari 100 meter yang cepat pula

c. Regresi sederhana daya ledak tungkai terhadap kecepatan lari 100 meter pada siswa SMK Negeri 2 Makassar.

Data daya ledak tungkai diperoleh melalui tes standing broad jump. Untuk mengetahui keeratan kontribusi daya ledak tungkai terhadap kecepatan lari 100 meter dilakukan analisis regresi. Rangkuman hasil analisis data dapat dilihat pada tabel 5.

Tabel 5. Rangkuman hasil analisis regresi daya ledak tungkai terhadap kecepatan lari 100 meter.

\begin{tabular}{cccl}
\hline Variabel & $\mathrm{R}_{0}$ & $\mathrm{P}$ & Keterangan \\
\hline DLT $(\mathrm{X} 3)$ & 0.651 & 0.000 & Signifikan \\
$\operatorname{L100M(Y)}$ & & & \\
\hline
\end{tabular}


Berdasarkan tabel 5 di atas terlihat bahwa hasil perhitungan regresi, diperoleh dengan nilai regresi $\mathrm{R}$ hitung $(\mathrm{Ro})=-0.651(\mathrm{P}<0,05)$, berarti ada kontribusi yang signifikan daya ledak tungkai terhadap kecepatan lari 100 meter pada siswa SMK Negeri 2 Makassar. Dengan demikian jika siswa memiliki daya ledak tungkai yang kuat akan diikuti dengan hasil kecepatan lari 100 meter yang cepat.

d. Regresi ganda kecepatan bergerak, reaksi kaki, dan daya ledak tungkai terhadap kecepatan lari 100 meter pada siswa SMK Negeri 2 Makassar

Regresi ganda dilakukan untuk mengetahui keterkaitan variabel bebas dengan variabel terikat secara bersama-sama yaitu mengetahui keeratan kontribusi kecepatan bergerak, reaksi kaki, dan daya ledak tungkai terhadap kecepatan lari 100 meter. Rangkuman hasil analisisnya dapat dilihat pada tabel 6.

Tabel 6. Hasil analisis regresi kecepatan bergerak, reaksi kaki, dan daya ledak tungkai terhadap kecepatan lari 100 meter siswa SMK Negeri 2 Makassar

\begin{tabular}{ccccc}
\hline Variabel & $\mathrm{R}_{0}$ & $\mathrm{~F}_{0}$ & $\mathrm{P}$ & Keterangan \\
\hline KBG (X1), RK (X2), DLT (X3) & & & & Signifikan \\
L100M (Y) & 0.861 & 34.380 & 0.000 & \\
\hline
\end{tabular}

Berdasarkan tabel 5 di atas terlihat hasil perhitungan regresi Ganda, diperoleh nilai $\mathrm{R}$ hitung $(\mathrm{Ro})=0.861$, setelah dilakukan uji signifikan dengan menggunakan uji $\mathrm{F}$ diperoleh $\mathrm{F}$ hitung $=34.380(\mathrm{P}<0,05)$, berarti ada kontribusi yang signifikan kecepatan bergerak, reaksi kaki, dan daya ledak tungkai terhadap kecepatan lari 100 meter pada siswa SMK Negeri 2 Makassar.

\section{PEMBAHASAN}

Hasil-hasil analisis kontribusi antara ketiga variabel bebas dengan satu variabel terikat dalam pengujian hipotesis perlu dikaji lebih lanjut dengan memberikan interprestasi keterkaitan antara hasil analisis yang dicapai dengan teori-teori yang mendasari penelitian ini. Penjelasan ini diperlukan agar dapat 
diketahui kesesuaian teori-teori yang dikemukakan dengan hasil penelitian yang diperoleh.

1. Ada kontribusi yang signifikan kecepatan bergerak terhadap kecepatan lari 100 meter pada siswa SMK Negeri 2 Makassar

Kecepatan bergerak merupakan komponen yang sangat penting guna meningkatkan kecepatan lari 100 meter secara keseluruhan. Dimana kecepatan gerak tungkai untuk melakukan gerakan langkah kaki secara berulang-ulang dalam menempuh jarak lari 100 meter akan menentukan kemampuan untuk mencapai kecepatan maksimal, sehingga jarak tersebut dapat dicapai dalam waktu sesingkat-singkatnya. kecepatan bergerak merupakan daya penggerak setiap aktifitas lari 100 meter yang dilakukan. Selain itu kecepatan bergerak adalah komponen fisik yang menyangkut kecepatan seorang atlet pada saat mempergunakan otot-ototnya menerima beban dalam waktu kerja tersebut. Peranan kecepatan bergerak sangat penting pada gerakan lari 100 meter, sebab dalam gerakan ini siswa harus cukup cepat untuk melakukan lari 100 meter. Selain itu kecepatan bergerak sangat menunjang ketangkasan atau keterampilan lari 100 meter. Untuk itu, dapat pula dikatakan bahwa kecepatan merupakan kemampuan otot untuk melakukan gerakan cepat dalam waktu yang relatif singkat. Pada saat lari cepat 100 meter, kecepatan sangat diperlukan oleh faktor kekuatan otot, elastisitas otot. Kekuatan otot, dan elastisitas otot mutlak diperlukan olahragawan, khususnya pelari jarak pendek. Tugas pelari jarak pendek ialah memindahkan berat badan sejauh 100 meter dalam waktu yang sesingkat mungkin. Makin cepat bergerak makin mudah ia dapat memindahkan berat badannya, dan hasilnya adalah makin pendek waktu yang dibutuhkan atau makin baik hasil waktu yang dicapai. Adapun sumbangan yang diberikan kecepatan bergerak terhadap kecepatan lari 100 meter sebesar $52.10 \%$.

2. Ada kontribusi yang signifikan reaksi kaki terhadap kecepatan lari 100 meter pada siswa SMK Negeri 2 Makassar.

Reaksi adalah kemampuan seseorang segera bertindak secepatnya dalam menanggapi rangsangan-rangsangan yang datang lewat indera, syaraf atau feeling 
lainnya. Rangsangan dapat berupa sinar yang diterima oleh indera mata, suara atau bunyi yang diterima oleh indera telinga, sentuhan yang diterima oleh indera kulit dan posisi yang diterima oleh alat keseimbangan dalam tubuh. Rangsangan yang paling sering dialami yang erat kaitannya dengan waktu reaksi adalah bunyi letusan pistol yang diterima oleh indera telinga pada waktu start pada cabang atletik nomor lari khususnya lari 100 meter. Semua rangsangan yang diterima oleh alat penerima atau panca indera atau reseptor ini, dikirim oleh urat saraf aferen ke sistim syaraf pusat (otak). Setelah dipelajari dan diolah di sistem ini, kemudian ada perintah (dari otak), melalui urat syaraf aferen menuju ke efektor yakni otot skeletal untuk bereaksi. Waktu yang dibutuhkan sejak rangsangan mulai diterima oleh reseptor (panca indera) sampai efektor (otot) bereaksi terhadap rangsangan tersebut, waktu inilah yang disebut waktu reaksi.agar lebih jelas, secara singkat pejalanan mulai dari ada rangsangan sampai timbul reaksi. Kualitas reaksi kaki memungkinkan memanfaatkan ruang gerak perototan secara maksimal. Sehingga pada saat melakukan lari 100 meter sangat membutuhkan reaksi kaki yang cepat setelah menerima rangsangan yang diterima oleh otot-otot yang elastis. Ini berarti bahwa dengan memiliki reaksi kaki yang cepat memudahkan seorang pelari untuk melakukan gerakan lari 100 meter. Ini dapat dibuktikan dengan besarnya sumbangan yang diberikan. Adapun sumbangan yang diberikan reaksi kaki terhadap kecepatan lari 100 meter pada sebesar $55.80 \%$.

3. Ada kontribusi yang signifikan daya ledak tungkai terhadap kecepatan lari 100 meter pada siswa SMK Negeri 2 Makassar.

Hasil yang diperoleh tersebut apabila dikaitkan dengan kerangka berpikir dan teori-teori yang mendasarinya, pada dasarnya hasil penelitian ini mendukung teori yang ada. Secara umum daya ledak dikenal sebagai salah satu komponen fisik yang sangat dibutuhkan dalam berabagi cabang olahraga. Dimana daya ledak tungkai merupakan kemampuan otot-otot tungkai untuk melakukan kekuatan yang maksimum dan dilakukan dalam waktu sependek-pendeknya. Selain itu daya ledak tungkai juga akan memiliki kemampuan otot-otot yang dapat mengatasi tahan dengan kontraksi yang sangat cepat. Daya ledak dapat dikembangkan 
melalui pembinaan unsur kekuatan dan kecepatan, kekuatan dan kecepatan otot merupakan dua komponen fisik yang dapat dipadukan dalam suatu pola gerak sehingga menimbulkan kemampuan daya ledak atau power dalam mengerahkan tenaga maksimal dalam waktu yang singkat. Daya ledak tungkai yang baik akan menghasilkan kecepatan lari 100 meter, dimana pergerakan kaki saat akan menolak dan membawa tubuh ke depan akan semakin cepat. Selain itut kaki ayun sebagai gaya akan memberikan momentum yang cepat saat sedang berlari. Adapun sumbangan yang dapat diberikan daya ledak tungkai terhadap kecepatan lari 100 meter pada sebesar $42.40 \%$.

4. Ada kontribusi yang signifikan secara bersama-sama kecepatan bergerak, reaksi kaki, dan daya ledak tungkai terhadap kecepatan lari 100 meter pada siswa SMK Negeri 2 Makassar.

Hasil yang diperoleh tersebut apabila dikaitkan dengan kerangka berpikir dan teori-teori yang mendasarinya, pada dasarnya hasil penelitian ini mendukung teori yang ada. Hal ini dapat dijelaskan bahwa apabila siswa didukung kecepatan bergerak, reaksi kaki, dan daya ledak tungkai yang baik maka siswa tersebut dapat melakukan gerakan lari 100 meter dan mampu memanfaatkan kecepatan bergerak dan reaksi kaki serta mampu mempertahankan posisi tubuh. Juga pemanfaatan kerja otot-otot yang berperan pada tungkai. Sehingga pada saat melakukan lari 100 meter dapat dilakukan dengan seefisien mungkin. Adapun sumbangan yang diberikan secara bersama-sama kecepatan bergerak, reaksi kaki dan daya ledak tungkai terhadap kecepatan lari 100 meter pada sebesar $74.40 \%$.

\section{KESIMPULAN}

Berdasarkan hasil analisis data yang didapatkan, berikut ini adalah kesimpulan yang didapatkan, antara lain adalah bahwa kecepatan bergerak, reaksi kaki, dan daya ledak tungkai memberikan kontribusi yang signifikan terhadap kecepatan lari 100 meter. Hasil penelitian ini bisa dijadikan acuan kepada para pelatih dan guru olahraga dalam mengajar atau melatih cabang olahraga lari 100 meter. Namun untuk pengembangan lebih lanjut pada penelitian lainnya agar 
menlaksanakan pada ruang lingkup yang lebih besar agar menjadi gambaran pengembangan ilmu selanjutnya.

\section{DAFTAR PUSTAKA}

Aswan, Andi Muhammad, and Muhammad Harliawan. 2019. "Perbandingan Kadar Asam Laktat Setelah Bermain Bolabasket." Kesehatan dan olahraga 3(2):76-84.

Bafirman, Bafirman, and Asep Sujana Wahyuri. 2019. "Pembentukan Kondisi Fisik."

Bahagia, Yoyo. 2012. "Pembelajaran Atletik." Jakarta: direktorat jendral pendidikan dasar dan menengah.

Jarver, Jess. 2005. "belajar dan Berlatih Atletik.” Bandung: cv. Pionir jaya.

Lumintuarso, Ria. 2013. “Teori Kepelatihan Olahraga.” Jakarta: lankor.

Muhtar, Tatang, and Riana Irawati. 2009. Atletik. UPI sumedang press.

Mureika, J. R. 2005. "The Effects of temperature, pressure, and humidity variations on 100 meter sprint performances." Can j phys.

Sugarwanto, sugarwanto, and Ardo Okilanda. 2020. "pengaruh latihan single leg hops terhadap hasil lompat jangkit siswa smp 1 sungai lilin." Kinestetik: jurnal ilmiah pendidikan jasmani 4(1):85-89.

Sugiyono. 2016. "Metode Penelitian pendidikan (pendekatan kuantitatif,kualitatif, dan R\&D).”

Tangkudung, James, and Wahyuningtyas Puspitorini. 2006. "Kepelatihan Olahraga Pembinaan Prestasi Olahraga." Jakarta: cerdas jaya.

Widiastuti. 2011. "tes dan pengukuran olahraga." Jakarta: PT. Bumi timur jaya. 